\title{
PENGARUH BIBLIOTERAPI TERHADAP KECEMASAN HOSPITALISASI ANAK USIA PRASEKOLAH DI RUMAH SAKIT MUHAMMADIYAH PALEMBANG
}

\author{
Marwan Riki Ginanjar', Miranti Florencia Iswari ${ }^{2}$, Noftalina ${ }^{3}$ \\ ${ }^{123}$ Program Studi Ilmu Keperawatan, STIKes Muhammadiyah Palembang \\ ginanjar.marky@gmail.com ${ }^{1}$ \\ umydirajuna@gmail.com ${ }^{2}$ \\ noftalina115@gmail.com ${ }^{3}$
}

\begin{abstract}
ABSTRAK
Latar belakang: Hospitalisasi dapat menimbulkan kecemasan pada anak prasekolah. Kecemasan anak prasekolah akibat hospitalisasi dapat diminimalisirdengan bermain, salah satunya menggunakan buku cerita. Pemanfaat buku sebagai media terapi disebut juga dengan Biblioterapi. Tujuan:Tujuan penelitian ini untuk mengetahui pengaruh biblioterapi terhadap kecemasan hospitalisasi pada anak usia prasekolah di Rumah Sakit Muhammadiyah Palembang. Metode:Penelitian menggunakan metode pre-experiment dengan rancangan One Group Pretest-postest. Kecemasan diukur dengan kuisioner kecemasan. Sampel penelitian ini adalah sebagian anak yang mengalami hospitalisasi di RS Muhammadiyah Palembang sebanyak 25 anak. Pengumpulan data dilakukan pada bulan April - Mei 2019.. Uji Statistik dengan mengunakan statistik parametrik uji T-test dependent.Hasil:Rata-rata nilai kecemasan siswa sebelum dan setelah dilakukan intervensi biblioterapi adalah 56,84 dan 3,35 dengan nilai $p$ value $<0,001$ yang artinya ada pengaruh biblioterapi terhadap kecemasan hospitalisasi pada anak prasekolah.
\end{abstract}

\section{Kata Kunci: Anak prasekolah, Biblioterapi, Hospitalisasi, Kecemasan}

\section{ABSTRACT}

Background: Hospitalization can cause anxiety in children. When children experience anxiety at the hospital, children will usually play using books. Use of books as a therapeutic medium is also called Bibliotherapy. Purpose: of this study was to determine the effect of Bibliotherapy on the anxiety of hospitalization in preschool children at the Muhammadiyah hospital in Palembang.Methode: This research method uses preexperimental research methods with one group pre-post test design with 25 responden. Data collected at April - May 2019. $T$ Test dependent used to analysis the result.Results:The Mean of Anxiety before and after intervention is 56,84 dan 3,35p value $<0.001$, which means that there is a significant relationship between bibliotherapy to the hospitalization anxiety in preschool children at the Muhammadiyah Hospital Palembang.

Keywords: Anxiety, Bibliotherapy, Hospitalization, Preschool

\section{PENDAHULUAN}

Anak prasekolah merupakan periode kanak-kanak awal antara usia 3-6 tahun.
Pada usia ini anak mampu melakukan berbagai gerakan seperti berlari, melempar, menari, berhitung. Anak 
prasekolah yaituanak yang berusia 3-6 tahun. Anak usia prasekolah memiliki kelemahan seperti kelemahan imunitas yang lebih rendah dari pada orang dewasa sehingga apabila anak sakit maka anak akan mengalami resiko infeksi yang lebih tinggi dari orang dewasa, anak prasekolah juga rentan mengalami jatuh dan cidera sehingga menyebabkan anak masuk rumah sakit.

Berdasarkan data (United Nations Childern's Find) UNICEF tahun 2017, jumlah anak usia prasekolah di 3 negara terbesar dunia mencapai 148 juta 498 anak dengan insiden anak di rawat di rumah sakit 57 juta anak setiap tahunnya. Indonesia jumlah usia anak prasekolah (3-6 tahun) berdasarkan Survey Nasional (SUSENAS) sebesar $30,82 \%$ dari total penduduk Indonesia, anak-anak di Indonesia yang menjalani hospitalisasi diperkirakan 35 per 1000 anak (Rini, 2013)

Menurut WHO, hospitalisasi merupakan pengalaman yang mengancam ketika anak menjalani hospitalisasi karena stressor yang dihadapi dapat menimbulkan perasaan tidak aman (WHO, 2012). Penyebab dari kecemasan pada anak yang di rawat inap (hospitalisasi) dipengaruhi oleh banyak faktor, baik faktor dari ketidaksukaan anak pada lingkungan rumah sakit juga disebabkan oleh ruangan rumah sakit yang ramai/gaduh, lingkungan yang panas, fasilitas permainan yang tidak memadai, dan makanan rumah sakit yang mungkin terasa hambar dan tidak enak (Gunarsa, 2012).

Anak akan menunjukkan berbagai reaksi terhadap hospitalisasi seperti efek psiologis masalah kesehatan terdapat juga efek psikologis dan hosptalisasi pada anak (Kyle, 2015). efek psiologis yaitu sebagai berikut: ansietas dan ketakutan, ansietas perpisahan, dan kehilangan kontrol.

Semakin anak cemas, maka semakin berpengaruh pada proses penyembuhan, yaitu menurunnya respon imun. Jika kecemasan anak selama hospitalisasi dapat diatasi, diharapkan anak akan lebih koopratif dan merasa lebih nyaman sehingga akan mempercepat penyembuhan penyakit dan memperpendek lama rawat di rumah sakit (Apriliawati, 2011).

Reaksi pada saat hospitalisasi berbeda-beda tergantung usia anak. Pada saat usia prasekolah, reaksi yang sering muncul pada umumnya dapat di gambarkan seperti sedih, takut dan bersalah karena menghadapi sesuatu yang belum dialaminya sebelumnya, rasa tidak aman, rasa tidak nyaman, perasaan 
kehilangan sesuatu yang biasa dialami dan sesuatu yang dirasakan menyakitkan.

Oleh karena itu, pada saat anak mengalami kecemasan di rumah sakit, untuk menghilangkan kecemasannya bisa dilakukan dengan bermain, yaitu dengan memberikan suatu permainan yang unik dan dapat menarik perhatian anak (Wong, 2009).

Pada saat anak mengalami kecemasan dirumah sakit, untuk menghilangkan kecemasannya bisa dilakukan dengan bermain, yaitu dengan memberikan suatu permainan yang unik dan dapat menarik perhatian anak (Wong, 2009). Terapi bermain atau play terapy diindikasikan sebagai salah satu jenis terapi yang cocok terapkan pada anak, anak dapat mengekspresikan perasaan mereka melalui permainan tersebut, salah satunya menggunakan buku cerita bergambar atau buku ilustrasi(Susana, 2011). Anak-anak dapat membawa bukubuku favorit, permainan, dan boneka hewan ke rumah sakit. Mereka lebih menikmati dibacakan cerita atau memegang boneka favorit. Dengan menggunakan buku anak dapat menghubungkan pengalaman personalnya seperti yang ada di cerita di dalam buku dan selanjutnya dapat digunakan sebagai dasar untuk diskusi (Apriliawati, 2011).
Pemanfaatan buku sebagai media terapi disebut dengan biblioterapi (Suparyo, 2010). Biblioterapi ini merupakan aktivitas terapi menggunakan buku yang disesuaikan dengan usia pasien dalam terapi pengobatan, dan dilanjutkan dengan diskusi atau perbincangan sesuai topik masalah kehidupan yang sesuai dengan kondisi yang dialamioleh pasien (Oppenheimer, 2010). Biblioterapi juga bisa menggunakan buku cerita bergambar, karena dengan gambar anak akan dapat dengan mudah terhibur dan tertarik untuk melihat dengan senang hati (Kusuma, 2013).Buku cerita bergambar merupakan buku bacaan cerita yang menampilkan teks narasi secara verbal dan disertai gambar-gambar ilustrasi yang mendidik. Buku cerita bergambar memiliki 6 jenis, seperti, fiksi, historis, biografi, cerita rakyat, kisah nyata. Karakteristikyang harus ada dalam buku cerita bergambar yaitu bersifat ringkas dan langsung, berisi konsep-konsep yang berseri, konsep yang ditulis dapat dipahami oleh anak-anak, gaya penulisan yang sederhana, terdapat ilustrasi yang melengkapi teks (Kusuma, 2013).

Menurut hasil penelitianYuan biblioterapi secara signifikan lebih efektif digunakan dalam terapi mental bagi anak dan remaja saat hospitalisasi di 
bandingkan dengan anak dan remaja yang di kelompok kontrol (Yuan, 2017).

Dalam penelitian Arum dkk, didapatkan hasil biblioterapi dan guided imagery sangat berpengaruh terhadap penurunan kecemasan saat hospitalisasi pada anak prasekolah (Purnawati, 2016). Penelitian tentang biblioterapi sangat berpengaruh dalam menurunkan tingkat kecemasan anak saat hospitalisasi juga di dudukung oleh penelitianApriza dari hasil penelitian tersebut didapatkan hasil ada hubungan yang bermakna antara pengaruh biblioterapi dengan buku cerita bergambar terhadap tingkat kecemasan efek hospitalisasi pada anak prasekolah (Apriza, 2017).

Berdasarkan hasil studi pendahuluan yang dilakukan peneliti di RS Muhammadiyah Palembang di dapatkan hasil bahwa data 3 bulan terakhir dari bulan November sampai bulan januari 2018 \& 2019 jumlah pasien anak dari umur 1-14 tahun yang menjalani rawat inap dengan 10 penyakit tertinggi yaitu 14 tahun sebanyak 82 anak dan 5-14 tahun sebanyak 107 anak di ruang rawat inap Rasyid Thalib di RS Muhammadiyah Palembang. Hasil observasi yang dilakukan peneliti di ruang rawat inap anak di RS Muhammadiyah Palembang didapatkan bahwa anak yang dirawat di rumah sakit sering menunjukkan reaksi kecemasan. Anak yang menjalani perawatan, anak menjadi sering gelisah, rewel dan selalu ingin ditemani saat menjalani proses perawatan. Dan dari hasil wawancara pada salah satu orang tua pasien, mengatakan bahwa anaknya sering menangis dan mengatakan ingin pulang. Penyebab kecemasan yang dialami juga beragam, mulai dari rasa cemas terhadap petugas kesehatan serta tindakan medis, ataupun rasa cemas karena rasa nyeri yang dialami.

Hasil observasi dan wawancara dengan perawat, didapatkan bahwa penerapan Biblioterapi belum pernah dilakukan oleh perawat pada ruang rawat inap anak Rasyid Thalib di RS Muhammadiyah Palembang. Berdasarkan penjelasan tersebut penulis tertarik untuk meneliti"Pengaruh Biblioterapi Terhadap Kecemasan Anak Prasekolah yang Mengalami Hospitalisasi di Rumah Sakit Muhammadiyah Palembang".

\section{METODE PENELITIAN}

Jenis penelitian ini adalah kuantitatif, dengan menggunakan desain yaitu pre experimental. Kelompok subjek diobservasi sebelum dilakukan intervensi kemudian diobservasi lagi setelah intervensi. Desain rancangan ini adalah One group pre-post test. Penelitian ini dilaksanakan pada tanggal 12 April- 3 
Mei 2019 di ruang rawat inap anak rumah sakit Muhammadiyah Palembang.

Populasi dalam penelitian ini adalah anak prasekolah (usia 3-6 tahun) yang menjalani hospitalisasi di rumah sakit Muhammadiyah Palembang, jumlah sampel pada penelitian ini 25 anak, dengan menggunakan teknik purposive sampling.

Alat pengumpulan data yang digunakan pada penelitian ini berupa penyebaran kuisioner kecemasan dengan beberapa pertanyaan kepada orang tua responden untuk menilai kecemasan anak. Anak dikatakan cemas jika jawaban pertanyaan menunjukkan tanda-tanda kecemasan. Semakin banyak dan sering tanda kecemasan maka semakin cemas anak tersebut. Analisa data yang digunakan adalah analisa univariat dan bivariat. Analisa bivariat menggunakan uji T-test dependent dengan tingkat kepercayaaan $95 \%$ dan tingkat kemaknaan $p$ value $9 \leq 0,05$. Analisa data menggunakan bantuan program komputerisasi.

\section{HASILPENELITIAN}

Hasil Penelitian dilihat dari hasil univariat dan bivariat.

Tabel 1.1

Rata-rata UsiaResponden Yang MengalamiKecemasan Akibat Hospitalisasi

\begin{tabular}{cccccc}
\hline Karakteristik & Mean & Median & Min & Max & SD \\
\hline Usia & 4,640 & 4,00 & 3 & 6 & 1,036
\end{tabular}

Tabel 1.2

DistribusiJenisKelaminResponden Yang MengalamiKecemasan Akibat Hospitalisasi

\begin{tabular}{|c|c|c|c|}
\hline No & JenisKelamin & $\mathbf{N}$ & Presentase $(\%)$ \\
\hline 1 & Laki-laki & 9 & 36 \\
\hline 2 & Perempuan & 16 & 64 \\
\hline & Jumlah & 25 & 100 \\
\hline
\end{tabular}

bahwa nilai rata-rata usia responden responden sebagian besar berjenis dengan nilai mean 4,640, usia minimal 3 kelamin perempuan sebanyak 16 tahun dan usia maksimal 6 tahun. Table responden $(64 \%)$.

Tabel 1.3

Rata-Rata Kecemasan Hospitalisasi Sebelum dan Sesudah Intervensi Biblioterapi

\begin{tabular}{lcccccc}
\multicolumn{1}{c}{ Variabel } & Mean & Median & SD & Min & Max & 95\% CI \\
\hline $\begin{array}{l}\text { Kecemasan sebelum } \\
\text { intervensi }\end{array}$ & 56,84 & 56,00 & 5,23 & 47 & 64 & $\begin{array}{c}54,68- \\
59,00\end{array}$ \\
\hline $\begin{array}{l}\text { Kecemasan sesudah } \\
\text { intervensi }\end{array}$ & 3,35 & 3,29 & 0,22 & 2,94 & 3,78 & $3,26-3,45$ \\
\hline
\end{tabular}


Dari Table 1.3 diatas nilai kecemasan siswa sebelum dilakukan intervensi biblioterapi didapatkan nilai kecemasan, Mean 56,84, minimum 47 dan maksimum 64, Std. Deviation 5,23 dan tingkat kepercayaan $95 \%$ kecemasan sebelum dilakukan intervensi biblio terapi berada pada rentang 54,68-59,00. Nilai

Table 1.4

Perbedaan Rata-Rata Kecemasan Hospitalisasi Sebelum Dan Sesudah Intervensi Biblioterapi

\begin{tabular}{|c|c|c|c|c|c|}
\hline \multirow[t]{2}{*}{ Variabel } & Sebelum & Sesudah & \multirow{2}{*}{$\begin{array}{c}\text { Beda } \\
\text { Rerata } \pm \\
\text { SD }\end{array}$} & \multirow[t]{2}{*}{ CI $95 \%$} & \multirow{2}{*}{$\begin{array}{c}\mathbf{P} \\
\text { Value }\end{array}$} \\
\hline & Rerata \pm SD & $\begin{array}{c}\text { Rerata } \pm \\
\text { SD }\end{array}$ & & & \\
\hline Kecemasan & $56,84 \pm 5,23$ & $3,35 \pm 0,22$ & $\begin{array}{c}-53,49 \pm- \\
3,13\end{array}$ & $\begin{array}{c}-51,42-(- \\
55,55)\end{array}$ & 0,000 \\
\hline
\end{tabular}

diketahui perbedaan rata-rata kecemasan sebelum dan sesudah intervensi biblioterapi pada pre-test kecemasan didapatkan nilai mean 56,84 dengan Std.Deviation 5,23, pada posttest kecemasan didapatkan nilai mean 3,35 dan Std.Deviation 0,22. Maka terjadi penurunan yang signifikan antara mean sebelum dan mean sesudah (-)53,49 dan didapatkan nilai $\mathrm{P}$ Value $<0,001(<0,05)$, maka keputusan statistiknya adalah ada perbedaan kecemasan sebelum dan sesudah dilakukan intervensi biblioterapi pada anak usia prasekolah di Rumah Sakit Muhammadiyah Palembang. kecemasan sesudah dilakukan intervensi biblioterapi didapatkan nilai kecemasan Mean 3,35, minimum 2,94 dan maksimum 3,78, Std.Deviation 0,22 dan tingkat kepercayaan 95\% kecemasan sesudah dilakukan intervensi biblioterapi berada pada rentang 3,26-3,45.

\section{PEMBAHASAN}

Pengaruh Biblioterapi dengan Buku Cerita Bergambar Terhadap Tingkat Kecemasan Efek Hospitalisasi Pada Anak Prasekolah Diruangan Anak di Rumah Sakit Muhammadiyah Palembang Tahun 2019.

Dari hasil penelitian di Rumah Sakit Muhammadiyah Palembang. Terdapat perbedaan rata-rata kecemasan sebelum dan sesudah dilakukan intervensi. Pada pre test kecemasan di dapatkan nilai mean 56,84. Pada post test kecemasan didapatkan nilai mean 3,35 denganselisih 52,71 dan Std. Deviation 5,01 .

Hasil uji statistic dengan menggunakan transformasi data didapatkan $\mathrm{P}$ Value $=<0,001 \quad(\mathrm{P}$ 
Value $<0,05)$, artinya ada perbedaan kecemasan sebelum dan sesudah dilakukan intervensi biblioterapi pada anak usia prasekolah yang menjalani hospitalisasi di Rumah Sakit Muhammadiyah Palembang.

Hasil penelitian ini sejalan dengan penelitian Apriza (2017) yang berjudul pengaruh biblioterapi dengan buku cerita bergambar terhadap tingkat kecemasan efek hospitalisasi pada anak prasekolah. Dengan didapatkan hasil yaitu $\mathrm{p}$ value $=$ $<0,001$ (p Value <0,05) yang berarti biblioterapi menggunakan media buku cerita bergambar efektif dalam menurunkan kecemasan anak prasekolah yang sedang menjalani hospitalisasi di Rumah Sakit Muhammadiyah Palembang.

Pada anak usia 3-6 tahun mengalami perkembangan fisik, kognitif, emosi. Perkembangan emosi anak selama masa awal kanak-kanak emosi sangat kuat. Saat ini merupakan saat ketidakseimbangan karena anak-anak“ keluar dari fokus" dalam arti bahwa ia mudah terbawa ledekan-ledekan, emosional sehingga sulit dibimbing dan diarahkan. Hal ini tampak mencolok pada anak usia prasekolah 3-6 tahun, meskipun pada umumnya hal ini berlaku pada hampir seluruh periode masa anak-anak awal (Mustofa, 2016). Pada penelitian ini di dominasi oleh anak perempuan. Hal ini sejalan dengan penelitian, dalam penelitian tersebut sebagian besar responden berjenis kelamin perempuan yaitu sebesar 20 responden $(57,1 \%)$ (Eliasa, 2014).

Kecemasan memiliki 2 bentuk: yaitu Trait Anxiety yaitu adanya rasa khawatir dan terancam yang menghinggapi diri individu terhadap kondisi yang sebenarnya tidak berbahaya dan State Anxiety yaitu kondisi emosional dan keadaan sementara pada diri individu dengan adanya perasaan tegang dan khawatir yang dirasakan secara sadar bersifat subjektif(Solikin, 2015). Biblioterapi dikatakan berhasil apabila, responden dapat meningkatkan pemahaman tingkah laku atau motivasi diri dan ketahanan mental (Hendyca, 2014).

Berdasarkan hasil penelitian, peneliti berpendapat bahwa ada perbedaan kecemasan anak sebelum dan sesudah dilakukan biblioterapi. Terlihat dari hasil mean responden sebelum dan sesudah dilakukan biblioterapi mengalami penurunan karena pelaksanaan penyampaiannya dengan media buku edukasi bergambar yang membuat anak-anak menjadi tertarik untuk mendengarkan dan mengikuti pesan yang ada didalam buku tersebut. 
Karena pada saat seseorang cemas amigdala di bagian otak besar bagian tengah sangat aktif dibanding korteks temporal dibagian otak kanan, membaca buku berperan penting dalam menstabilkan kinerja amigdala. Ketika seseorang terfokus pada buku, stress dan ketegangan yang tercipta oleh amigdala tersebut berkurang dan fokus seseorang itu menjadi lebih meningkat serta korteks temporal dibagian otak besar bagian kanan berfungsi normal dan emosi serta ketakutan menjadi mereda.

Dalam memberikan biblioterapi pada anak usia prasekolah hal terpenting yang harus diperhatikan yaitu penggunaan media yang bisa dengan mudah diterima oleh anak, seperti buku edukasi bergambar. Media buku edukasi bergambar cocok untuk anak usia prasekolah karena sangat praktis sehingga anak dapat menggunakan media ini untuk proses belajar memotivasi diri, mudah di ingat karena buku bergambar disajikan dengan pesan-pesan pendek yang memudahkan anak untuk mengingat pesan yang ada dalam buku tersebut. Hasil penelitian membuktikan bahwa penggunaan buku edukasi bergambar sangat efektif sebagai media untuk menurunkan kecemasan anak prasekolah. Hal ini dibuktikan dengan hasil yang didapatkan sebelum dilakukan biblioterapi nilai minimum kecemasan 47 dan nilai maksimum 64. Akan tetapi, hasilnya mengalami penurunan setelah dilakukan biblioterapi dengan menggunakan buku edukasi bergambar yaitu nilai minimum 18 dan maksimum 51.

Berdasarkan nilai kecemasan tertinggi sebelum dan sesudah dilakukan intervensi biblioterapi yaitu anak mengompol saat di rumah sakit menurun menjadi 14 .

Reaksi anak prasekolah ketika mengalami perawatan di rumah sakit adalah dengan menunjukkan reaksi perilaku seperti protes, putus asa dan regresi. Hal ini bisa dibuktikan dengan dengan anak tampak tidak aktif, sedih, tidak tertarik pada lingkungan, tidak komunikatif, mundur ke prilaku sebelumnya (misalnya: menghisap ibu jari, mengompol dan lain-lain) (Wong, 2009).

Pada saat anak mengompol susunan saraf pusat pada anak usia prasekolah belum matang sempurna serta kondisi fisik terganggu, kadar $\mathrm{ADH}$ dalam tubuh kurang atau akibat stress psikologi yang sering mengakibatkan anak cemas dan terkadang mengompol ketika tidur. Untuk mengatasi hal tersebut. Biblioterapi dapat menurunkan cemas seseorang. Pada saat orang cemas 
amigdala dibagian otak besar bagian tengah sangat aktif dibandingkan korteks temporal dibagian otak kanan. Dengan membaca buku dapat menstabilkan amigdala, ketika seseorang berfokus pada buku. Stress dan kecemasan akan berkurang dan focus menjadi meningkat serta korteks temporal diotak besar bagian kanan dapat berfungsi normal dan menurunkan stress serta ketakutan lebih mereda (Ratna Juita, 2012).

Nilai kecemasan sebelum dan sesudah intervensi biblioterapi terendah anak mengatakan bermimpi buruk menurun menjadi 40. Ketika anak yang menjalani hospitalisasi tidak menerima perlakuan psikologis apapun maka anak akan mengalami gangguan somatis adalah inti dari gangguan stress atau kecemasan, individu yang mengalami kecemasan sering diserang beberapa gejala tubuh yang menakutkan yang ditandai dengan pengalaman kewaspadaan yang berlebihan pada saraf otonom selama anak tersebut trauma, seperti denyut jantung menjadi cepat dan berdebar-debar serta gejala ini bisa menyebabkan gangguan tidur serta mimpi buruk. Dalam hal ini biblioterapi juga dapat menurunkan cemas seseorang, setelah amigdala seseorang menjadi stabil pada saat dilakukan biblioterapi maka trauma dan kewaspadaan dapat mereda dan pikiran menjadi rileks dikarenakan seseorang mengambil banyak pelajaran dari dalam buku yang telah dibacakan tersebut.

\section{KESIMPULAN DAN SARAN}

\section{Kesimpulan}

Berdasarkan penelitian yang dilakukan pada 25 responden tentang pengaruh biblioterapi terhadap kecemasan hospitalisasi pada anak usia prasekolah di Rumah Sakit Muhammadiyah Palembang didapatkan kesimpulan sebagai berikut:

1. Didapatkan nilai rata-rata kecemasan dengan mean 56,84 sebelum dilakukan intervensi biblioterapi buku edukasi bergambar di Rumah Sakit Muhammadiyah Palembang.

2. Didapatkan nilai rata-rata kecemasan dengan mean 3,35 sesudah dilakukan intervensi biblioterapi buku edukasi bergambar di Rumah Sakit Muhammadiyah Palembang.

3. Ada perbedaan nilai rata-rata kecemasan sebelum dan sesudah dilakukan intervensi biblioterapi buku edukasi bergambar pada anak usia prasekolah di Rumah Sakit Muhammadiyah Palembang didapatkan nilai $\mathrm{p}$ value $=<0,001$. 


\section{Saran}

a. BagiRumahSakit

Bagi rumah sakit agar dapat dibuat program khusus biblioterapi untuk pasien anak-anak yang sedang dirawat di ruang anak Rasyid Thalib. Bagi pihak rumah sakit disarankan agar lebih melengkapi fasilitas terapi untuk mengatasi kecemasan hospitalisasi pada anak-anak yang menjalani hospitalisasi seperti tersedianya tempat khusus bermain dan menyediakan buku-buku edukatif dan permainan edukatif dalam masa hospitalisasi. Sehingga kecemasan anak tidak menjadi masalah lagi dalam setiap asuhan keperawatan.

b. BagiPenelitiSelanjutnya

Diharapkan kepada peneliti selanjutnya dapat mengembangkan, membandingkan dan melanjutkan penelitian dengan variabel, metode, dan media yang berbeda. Berikut topik yang disarankan untuk penelitian selanjutnya.

\section{DAFTAR PUSTAKA}

1. Apriliawati, Anita (2011).

Bibliotherapy Dapat Menurunkan Tingkat Kecemasan Anak Usia Sekolah Yang Menjalani Hospitalisasi Di Rumah Sakit Islam
Jakarta. Nursing ScienceJurnal Keperawatan.

2. Apriza, (2017). Biblioterapi Dengan Buku Cerita Bergambar Terhadap Tingkat Kecemasan Efek Hospitalisasi pada Anak Prasekolah. Jurnal Obsesi: Jurnal Pendidikan Anak Usia Dini,Volume 1 Issue 2 (2017) Pages 105-110. ISSN: 25498959

3. Solikin A, (2015). Bibliotherapy Sebagai Sebuah Teknik Dalam Layanan Bimbingan Dan Konseling. Anterior Jurnal, Volume 14 Nomor 2, Hal 154-161

4. Purnawati D.A, Hartati S, Astuti R, (2016) Efektifitas Biblioterapi dan Guided Imagery Terhadap Tingkat Kecemasan Pada Anak Prasekolah Yang Menjalani Hospitalisasi Di RSUD TUGUREJO SEMARANG, Jurnal Ilmu Keperawatan (JIKK)

5. Eva Imania Eliasa, (2014) Bibliotherapy As A Method Of Meaningful Treatment.

6. Gunarsa (2012). Pengaruh biblioterapi dengan buku cerita bergambar terhadap tingkat kecemasan pada anak prasekolah saat pemasangan infuse di Rs Telogorejo Semarang. 
7. Kyle, T \& Carman, S. (2015). Buku Ajar keperawatan pediatrik edisi 1. Jakarta : Wolters Klowers EGC.

8. Kusuma, D. (2013). Perancang buku Pop-up Cerita Rakyat Bledhug Kuwu. Semarang : Balai Penerbit UNNES.

9. Mustofa, B (2016). Dasar-Dasar Pendidikan Anak Pra Sekolah : Yogyakarta. Penerbit Parama Ilmu.

10. Oppenheimer, C (2010). Use of bibliotherapy as a adjuctive therapy with bereaved children : a grand proposal. Tesis. Long Beach: California State University.

11. Putra, D. Setiawan Hendyca. (2014). Keperawatan Anak \& Tumbuh Kembang (I). Nuha Medika.

12. Rini, D. M., H, R. S., Rahmawati, I., Studi, P., \& Keperawatan, I. (2013). Hubungan penerapan Atraumatic Care dengan Kecemasan Anak Prasekolah Saat Proses Hospitalisasi di RSUD dr. H Koesnadi Kabupaten Bondowoso Regency.

13. Sarka Ade Susana dan Sri Hendarsih. (2011). Terapi Modalitas: Keperawatan Kesehatan Jiwa. Buku Kedokteran EGC, 2011.

14. Shuai Yuan. (2017). Comparative efficacy and acceptability of bibliotherapy for depression and anxiety disorders in children and adolescents : a meta-analysis of randomized clinical trials. Dovepress, open access to scientific and medical research

15. Suparyo, Y (2010). Bagaimana menerapkan Biblioterapi. (Pengaruh Biblioterapi dengan buku cerita bergambar terhadap tingkat kecemasan pada anak prasekolah saat pemasangan infuse $d i \quad R s$ Telogorejo Semarang

16. UNICEF. (2017). The World Bank Joint Child Malnutrition Estimates. 2017 edition. Tim Badan WHOUnicef-the world bank joint child malnuriton

estimates.http://www.who.int/nuthro wthdb/jme brochoure2017.pdf?ua=1.

17. Wong, D., dkk. (2009). Buku Ajar Keperawatan Pediatrik. Jakarta: EGC

18. World Health Organization (WHO), Angka Kematian Bayi. Amerika: WHO; 2012. 